\title{
The Influence of Abrasive Pretreatment on Hot Air Drying of Grape
}

\author{
Giuseppina Adiletta1, Wijitha Senadeera ${ }^{2}$, Loredana Liguori ${ }^{1}$, Alessio Crescitelli $^{3}$, \\ Donatella Albanese ${ }^{1}$, Paola Russo ${ }^{*}$ \\ ${ }^{1}$ Department of Industrial Engineering, University of Salerno, Fisciano, Italy \\ ${ }^{2}$ School of Chemistry Physics and Mechanical Engineering, Faculty of Science and Engineering, \\ Queensland University of Technology, Brisbane, Australia \\ ${ }^{3}$ Institute for Microelectronics and Microsystems, Napoli, Italy \\ ${ }^{4}$ Department of Chemical Engineering Materials Environment, University of Rome "La Sapienza", \\ Roma, Italy \\ Email: paola.russo@uniroma1.it
}

Received 20 February 2015; accepted 9 March 2015; published 13 March 2015

Copyright (C) 2015 by authors and Scientific Research Publishing Inc.

This work is licensed under the Creative Commons Attribution International License (CC BY). http://creativecommons.org/licenses/by/4.0/

cC) (i) Open Access

\begin{abstract}
The drying of grapes is a more complex process compared to the dehydration of other agricultural materials due to the necessity of a pretreatment operation prior to drying. Grape drying to produce raisins is a very slow process, due to the peculiar structure of grape peel, that is covered by a waxy layer. Its removal has been so far carried out by using several chemical pre-treatments. However, they cause heterogeneity in the waxes removal and create microscopic cracks. In this paper an abrasive pretreatment for enhancing the drying rate and preserving the grape samples is proposed. Two cultivars of grape were investigated: Regina white grape and Red Globe red grape. The drying kinetics of untreated and treated samples were studied using a convective oven at $50^{\circ} \mathrm{C}$. Fruit quality parameters such as sugar and organic acid contents, shrinkage, texture, peel damage (i.e. by SEM analysis) and rehydration capacity were studied to evaluate the effectiveness of abrasive pretreatment on raisins. Abrasive pretreatment contributed to reduce drying time and rehydration time. The treated and untreated dried grapes were significantly different $(p<0.05)$ in sugar and in tartaric acid content. On the contrary, no significant differences $(p<0.05)$ in malic and citric acids and in texture properties between untreated and treated samples were observed.
\end{abstract}

\section{Keywords}

Grape, Drying, Raisin, Abrasive Pretreatment, Sugar Content, Shrinkage, Texture, Rehydration

\footnotetext{
${ }^{*}$ Corresponding author.
} 


\section{Introduction}

Fresh grapes are very sensitive to microbial spoilage during storage, even under refrigerated conditions, having relatively high moisture contents (80\% - 85\% wet basis). Therefore, within a few weeks following harvest, they must either be consumed or processed into various products. Drying is the most common method for grape processing. It can process grapes into raisins for longer shelf-life by reducing the moisture content to a low level. Raisins can be consumed either directly as ready-to-eat food or as ingredients in biscuits, breads and porridges [1].

Traditionally raisins are obtained by sun drying of the fruit for eight to ten days, which substantially reduces water content. This drying method is cheap, but there is a risk of damage due to dust and insect infection [2] and the sensory quality can also be seriously damaged during exposure to sunlight [3]. Convective drying is one of the oldest and alternative dehydration methods in which hot air removes the water from the fruit surface. This creates a diffusion gradient in the food that moves the water from the interior to the outer surface [4]. However, this process decreases the quality of the final product [5]. Moreover, dehydration causes damages in texture, color, taste and nutritional value of food due to the high temperatures and long drying times required in the process [6]. The drying of grape should be carried out quickly (less exposure time to oxygen) and at relatively low drying temperature [7].

The peel of the grape plays a critical role in controlling the drying process. Grape peel consists of a wax layer as a protective barrier against fungal pathogens [8]. However, this coating reduces permeability and therefore hinders the process of water transfer [9] [10]. Due to this, prior to drying, several chemical and physical pretreatments are used to enhance permeability and increase the drying rate, while preserving the physical, chemical, nutritional and sensory qualities of the final product [7]. Dipping waxy fruits for several seconds in solution of ethyl oleate or other suitable compound (usually fatty acid derivatives used as wetting agents and emulsifiers) greatly reduces drying time [11] [12]. The effects of pretreatment solutions on seedless grapes during drying were reported in literature [13]. Chemical pretreatments normally break down the waxy cuticular fruit surface and creates microscopic cracks which increase moisture permeability. The best pretreatment method before drying of any fruit should reduce drying time while keeping high quality of product (color, nutritional properties, taste, etc.).

Di Matteo et al. [14] tested a new physical pretreatment method on seedless grape and showed that superficial abrasion of the berry peel using an inert abrasive material can be as effective as ethyl oleate. In a previous study [15], we found that treated white and red grapes showed reduced drying times due to faster release of moisture and lower color changes. Moreover, drying kinetics was modeled by several empirical models and the highest correlation coefficient was represented by two compartment model for the treated white and red grapes and Page model for untreated white and red grapes.

The purpose of the present work is to study the effect of the physical pretreatment, on two different cultivars of white and red grapes (Regina and Red Globe respectively) of Italy. The pretreatment consisted of superficial abrasion of the grape peel by an inert abrasive material to remove the cuticular waxy layer. Drying kinetics, sugar and organic acids contents, shrinkage, microstructure, texture properties and rehydration capacity were reported.

\section{Materials and Methods}

\subsection{Samples Preparation}

Grapes selected from Regina (white cultivar) and Red Globe (red cultivar) were used for the experiments. To ensure the uniformity of the physical characteristics of experimental materials, the grape samples with the similar size (Table 1) were selected from the same farm. Some physicochemical characteristics of grapes used are given in Table 1. Before drying, samples of white and red grapes were submitted to a physical abrasive pretreatment. The abrasion of the grape peel was carried out in a pilot system with motorized rotating drum created by Prof. Marisa Di Matteo, Department of Industrial Engineering, University of Salerno [10] [14]. The drum was made of plexiglass, lined inside with sandpaper. The rotation speed of drum was $9 \mathrm{rpm}$, the pretreatment time was 30 min. A patent is applying for this new system.

\subsection{Drying Experiments}

Drying of grapes was carried out in a convective dryer (Zanussi FCV/E6L3) at $50^{\circ} \mathrm{C}$ with an air velocity of 2.3 
Table 1. Main characteristics of the two cultivars.

\begin{tabular}{cccc}
\hline Fresh Sample & Moisture Content (g/g Sample) & Average Diameter $(\mathrm{mm})$ & Average Peel Thickness ${ }^{*}(\mu \mathrm{m})$ \\
\hline Regina White Grape & $0.78 \pm 0.01$ & $21.95 \pm 3.99$ & $44 \pm 1$ \\
Red Globe Red Grape & $0.80 \pm 0.01$ & $24.43 \pm 1.95$ & $41 \pm 1$ \\
\hline
\end{tabular}

$\mathrm{m} / \mathrm{s}$ until similar water content for both grapes (about $0.08 \mathrm{~g} / \mathrm{g}$ sample for white grape and $0.06 \mathrm{~g} / \mathrm{g}$ sample for red grape) was achieved. At regular intervals the samples were weighted by means of a digital balance (mod. Gibertini E42, Italia). Two kinds of samples were compared during drying: untreated grape and treated grape samples. Moisture ratio (MR) was calculated as the ratio between the actual $\left(\mathrm{M}_{t}\right)$ and the initial $\left(\mathrm{M}_{0}\right)$ moisture content. The results were reported as average of three sets of experiments.

\subsection{Sugar and Organic Acids Analysis}

The fructose and glucose contents were determined by HPLC method according to literature [10]. Organic acids were determined by ion exchange chromatography [16].

\subsection{Shrinkage Curves}

Samples were obtained during the drying experiments by taking six fruit berries for each cultivar. The length and diameter of the fruits were measured using a digital caliper micrometer. The shrinkage of the samples was then expressed as the ratio of decrease in sample volume $\left(\mathrm{V}_{0}-\mathrm{V}\right)$ and initial sample volume $\left(\mathrm{V}_{0}\right)$, where $\mathrm{V}$ is the volume at a given drying time.

\subsection{Texture Measurements}

Texture of dried samples was measured by means of Texture Profile Analysis (force-deformation) with a Texture Analyzer (Ametek Lloyd Instruments LRX plus, UK) provided with specific software (Nexygen batch 4.1). Each of the ten dried grapes used for tests was compressed between two parallel plates (diameter of $3.5 \mathrm{~cm}$ ) up to $50 \%$ of its initial thickness; two consecutive cycles of compression were performed on each sample with $5 \mathrm{~s}$ between cycles. The cross-head moved at a constant speed of $0.25 \mathrm{~mm} / \mathrm{sec}$. From the resulting force-deformation curve the following parameters were determined: hardness $(\mathrm{N})$, maximum force required to compress the sample; springiness, ability of sample to recover its original form after the deforming force is removed; chewiness $\left(\mathrm{N}^{*} \mathrm{~mm}\right)$, the work necessary to chew a solid sample to a steady state of swallowing.

\subsection{SEM Images}

The microstructure of grape peel samples was evaluated by images from Scanning Electron Microscope (SIGMA ZEISS, featuring GEMINI ${ }^{\circledR}$ technology). Samples were prior coated with a thin layer of gold in a sputter coater (AGAR Auto Sputter Coater, mod. 108 A, England) for $150 \mathrm{~s}$ [6].

\subsection{Rehydration Kinetics}

Rehydration kinetics was carried out at room temperature. The approximate volume ratio of dried fruits and water was kept as 1:30 [17]. The rehydrated samples were spread on absorbent paper for the removal of free water on the surface of berries. The change in weight was recorded at constant time intervals. The rehydration capacity, described as rehydration ratio, was calculated from the ratio of sample weight after and before the rehydration by using Equation (1):

$$
\text { Rehydration ratio }=\frac{\text { (weight of rehydrated samples) }}{\text { (weight of dried samples) }}
$$

\subsection{Statistical Analysis}

Experiments were performed in triplicate. Data reported are the mean and the standard deviation calculated from 
three replicates. The analysis of variance (ANOVA) at the level of significance $p<0.05$ using Student-NeumanKeuls test was applied to the data.

\section{Results and Discussion}

\subsection{Drying Kinetics}

To compare the effect of pretreatment on the drying kinetics of Regina and Red Globe grapes, the curves of MR versus drying time are shown in Figure 1 and Figure 2, respectively. It can be seen that MR of grape samples decreased with the increase of drying time and the abrasive pretreatment shortened the drying time significantly compared to the untreated samples. In particular, the moisture content of untreated white samples decreased slowly from $0.78 \pm 0.01 \mathrm{~g} / \mathrm{g}$ sample $(\mathrm{MR}=1)$ to $0.08 \pm 0.003 \mathrm{~g} / \mathrm{g}$ sample $(\mathrm{MR}=0.12)$ in $126 \mathrm{~h}$; whereas treated white samples showed a moisture loss from initial value $0.80 \pm 0.01 \mathrm{~g} / \mathrm{g}$ sample $(\mathrm{MR}=1)$ up to $0.06 \pm 0.003 \mathrm{~g} / \mathrm{g}$ sample $(\mathrm{MR}=$ 0.11 ) in only $50 \mathrm{~h}$. In a similar way, the treated red samples had a faster moisture loss with respect to untreated

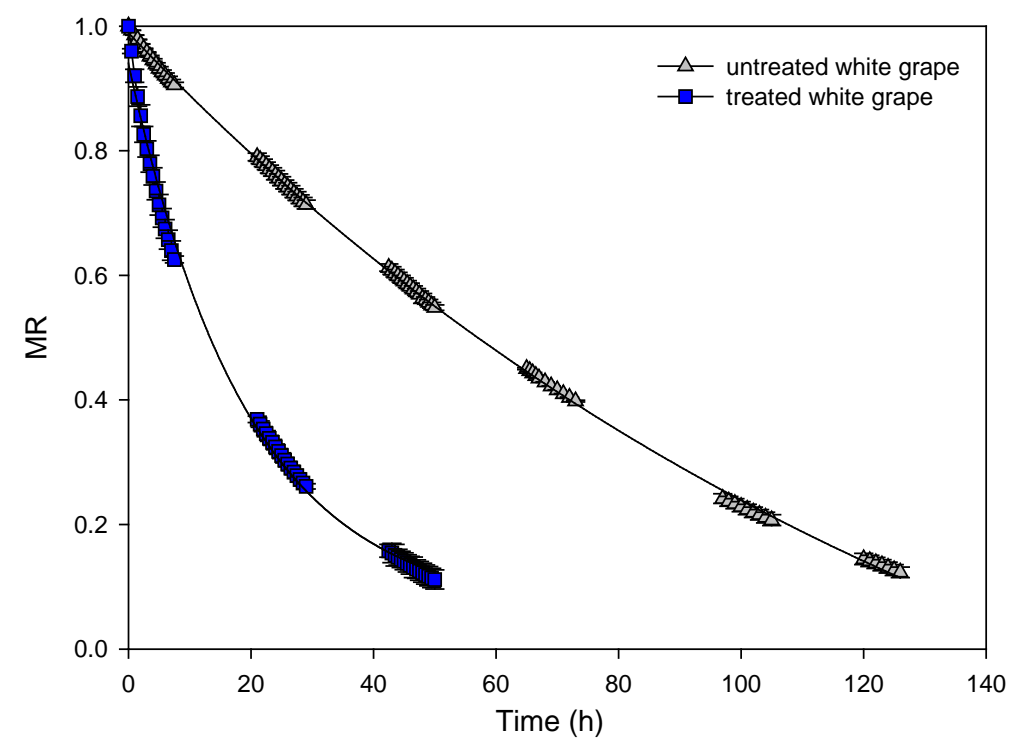

Figure 1. Moisture ratio of untreated and treated white grape during drying at $50^{\circ} \mathrm{C}$.

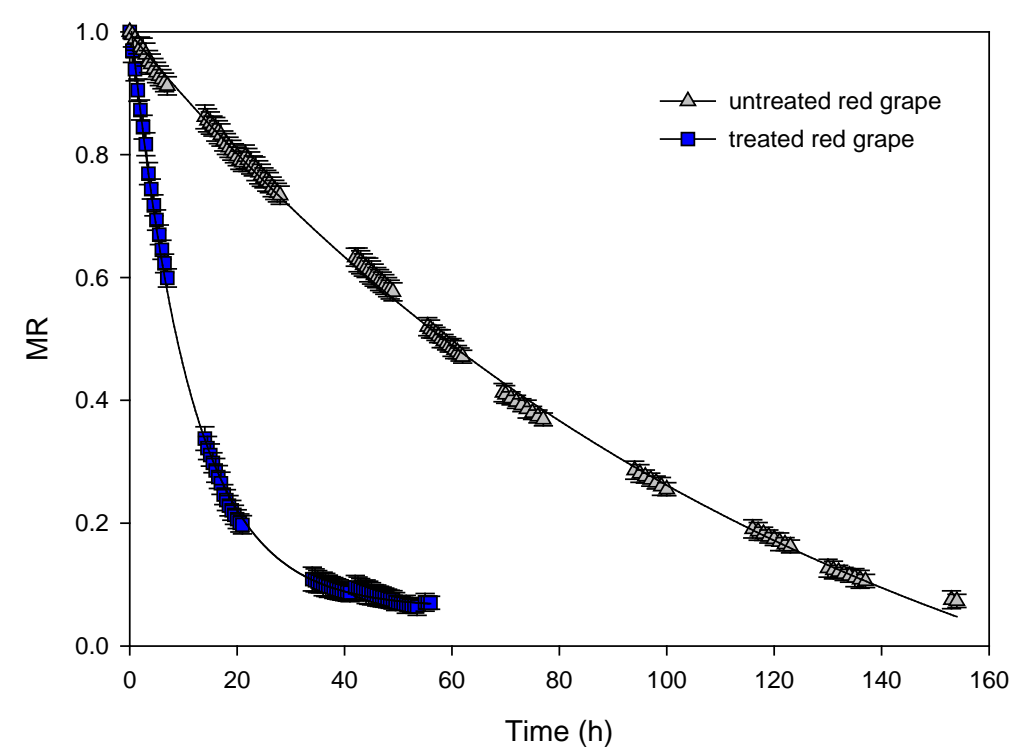

Figure 2. Moisture ratio of untreated and treated red grape during drying at $50^{\circ} \mathrm{C}$. 
ones: the drying time decreased from $154 \mathrm{~h}$, for untreated berries, to $56 \mathrm{~h}$ for treated ones. In summary, the pretreated grapes took $60 \%$ - $64 \%$ less drying time than those which were not pretreated, to reach the same final moisture content.

\subsection{Sugar and Organic Acids}

Raisins are a rich source of carbohydrate. Glucose and fructose are the main sugars detected in both grape cultivars. As reported by other authors for grapes [7] and plums [10], a reduction of sugar content was observed during drying, probably caused by non-enzymatic browning reactions (Figure 3 and Figure 4). About white grapes, a reduction of fructose content (about 26\%) was measured for both untreated and treated dried samples, while the decrease in glucose content (22\% and 13\%, respectively for untreated and treated grapes) was lower for treated raisins. With regard to red grape, at the end of drying process a higher decrease in sugar content, for both glucose and fructose, was observed for untreated samples (reduction of $47 \%$ in fructose and $40 \%$ in glucose) in comparison with the treated ones (a reduction of $22 \%$ in fructose and $12 \%$ in glucose). This behaviour was probably justified by the higher drying time required for untreated samples to reach the set moisture content.

The content of main organic acids (malic, tartaric and citric acids) was reported in Figure 5 and Figure 6. No significant differences $(p<0.05)$ in malic and citric acids content were observed between fresh and dried white grapes (for both untreated and treated). Tartaric acid was affected by the drying process with a $10 \%$ reduction in both dried samples. As regards red grape, only the untreated samples presented a loss of $7 \%$ in tartaric acid. Malic and citric acids were not affected by the drying process.

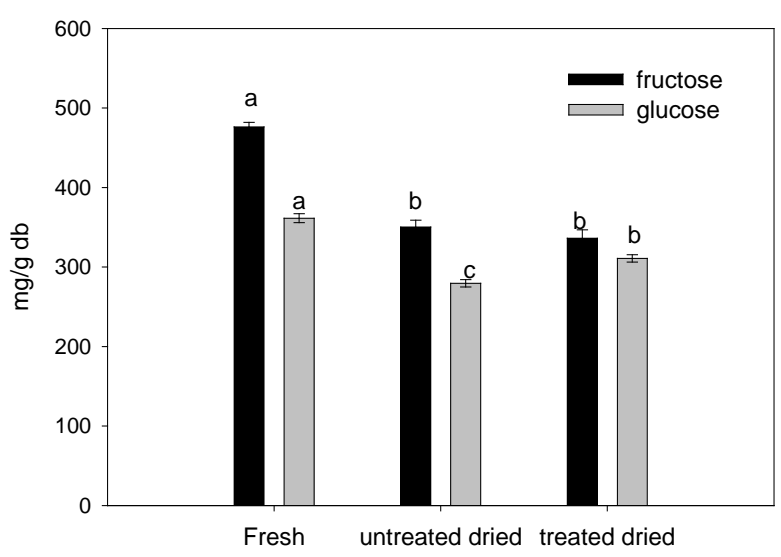

Figure 3. Sugar content in fresh and dried $\left(50^{\circ} \mathrm{C}\right)$ white grape. Values with different superscript letters are significantly different $(p<0.05)$.

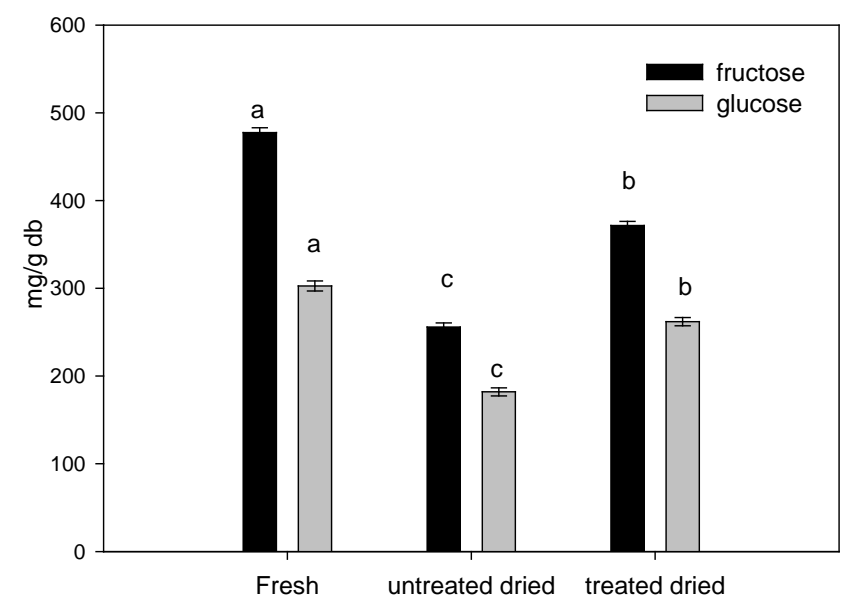

Figure 4. Sugar content in fresh and dried $\left(50^{\circ} \mathrm{C}\right)$ red grape. Values with different superscript letters are significantly different $(p<0.05)$. 


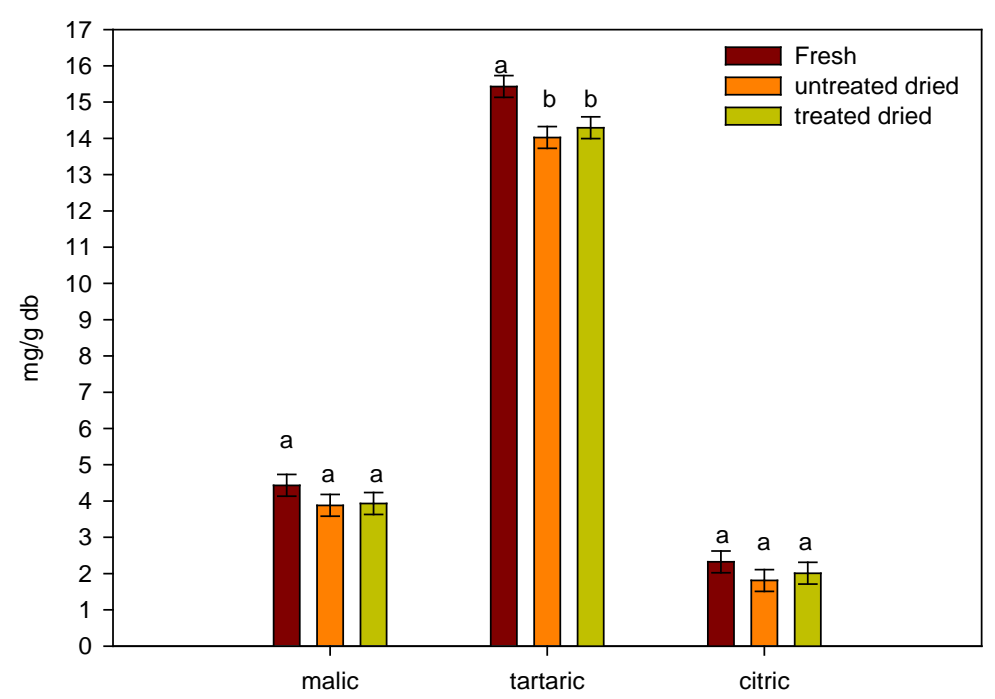

Figure 5. Organic acids in fresh and dried $\left(50^{\circ} \mathrm{C}\right)$ white grape. Values with different superscript letters are significantly different $(p<0.05)$.

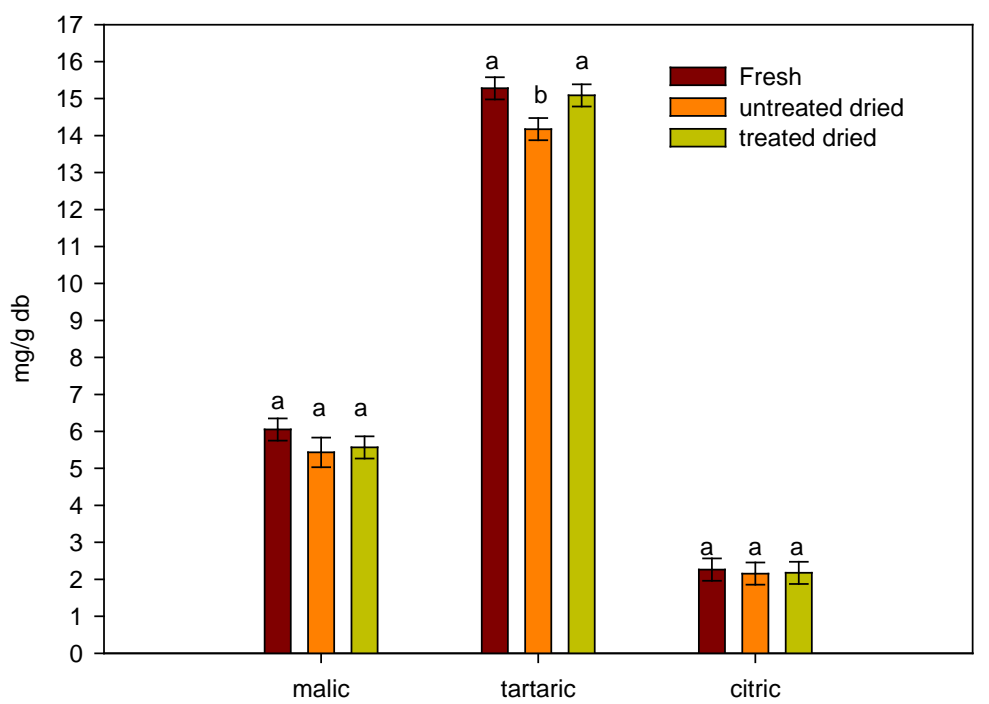

Figure 6. Organic acids in fresh and dried $\left(50^{\circ} \mathrm{C}\right)$ red grape. Values with different superscript letters are significantly different $(p<0.05)$.

\subsection{Shrinkage Curves}

Shrinkage of food materials has negative consequences on the quality of the dehydrated product and increases with the volume of removed water [18] [19]. As expected, a gradual overall shrinkage of the grape cells was observed with drying time. Disruption of cellular walls with consequent cellular collapse was clear from the experiments. At the end of drying, for white grape the volume change of untreated berries was about $35 \%$ and only $19 \%$ for treated ones. For red grape, the volume changed from about $40 \%$ for untreated samples to $30 \%$ for treated ones. For white grape the treated samples showed a reduction in sample volume lower than the volume of removed water during the whole drying process, especially for $\mathrm{V} / \mathrm{V}_{0}>0.6$. On the contrary, the untreated samples showed that the volume of removed water was similar to the reduction in sample volume (Figure 7).

Similar behavior for red untreated berries was observed (Figure 8). Treated red grape showed a reduction in sample volume higher than the volume of removed water during the initial stages of drying, but a lower shrinkage than untreated ones during the final stages $\left(\mathrm{V} / \mathrm{V}_{0}>0.6\right)$. By these results, it can be concluded that the abrasive pretreatment produced less shrinkage in white and red grapes at the end of drying process. Probably, the 


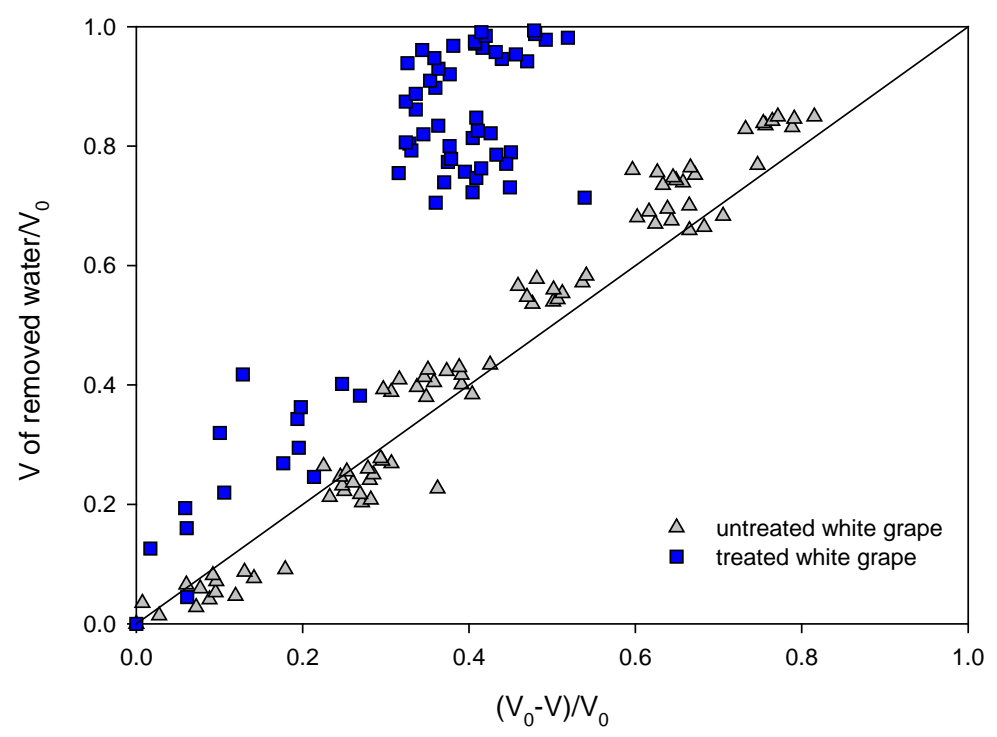

Figure 7. Ratio of volume of removed water vs. fractional decrease in sample volume for untreated and treated white grape. Solid line represents the diagonal.

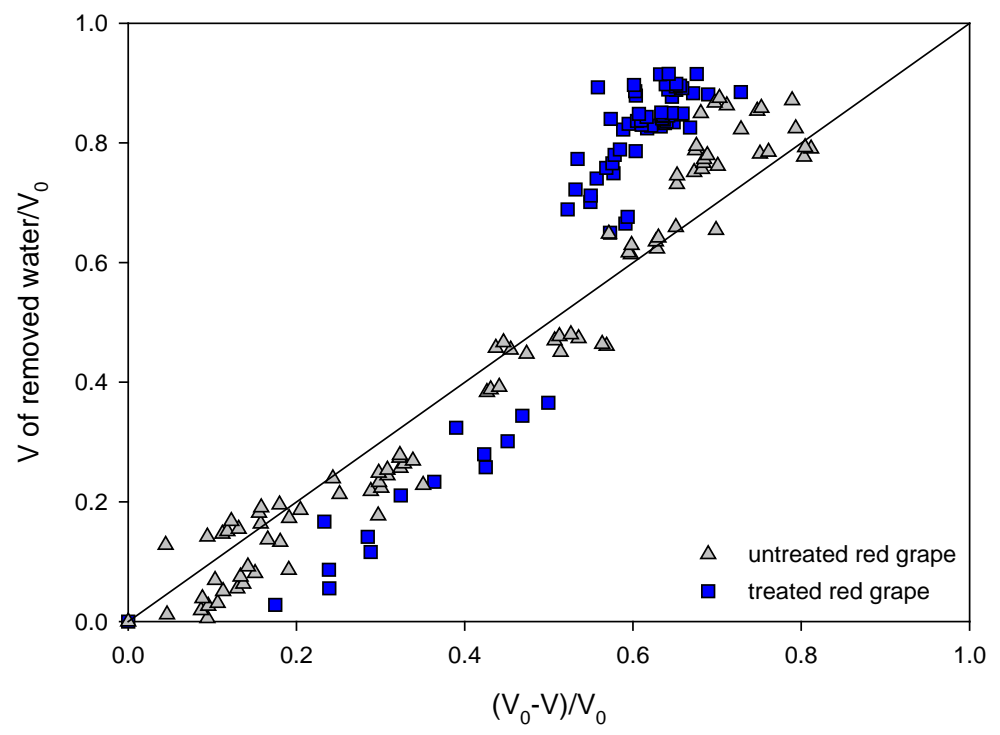

Figure 8. Ratio of volume of removed water vs. fractional decrease in sample volume for treated and untreated red grape. Solid line represents the diagonal.

absence of waxy on the peel determines, apart a faster diffusion of water from the inner to the outer zone, that the surface quickly becomes rigid and stopping the shrinkage.

\subsection{Texture Measurements}

Table 2 reported the results of the instrumental TPA attributes for the different dried grapes. Hardness is the force required to compress a food between the teeth or between the tongue and mouth, i.e. the force required to cause deformation [20]. The springiness is the ability to regain shape after compression [20], while the chewiness measures the energy required to disintegrate a food as to be swallowed [20]. Statistical analysis showed that, for each cultivar, untreated and treated dried samples were similar in terms of hardness, springiness and chewiness. Among the cultivars, the dried samples resulted significantly similar in terms of springiness. But the dried white grapes were harder than red ones and, correspondingly, higher chewiness values were measured for them 
with respect to red grapes.

\subsection{SEM Measurements}

The wax is made up of an amorphous layer, consisting of a series of overlapping hydrophobic platelets and intracuticular wax that is present in structure of the outer epidermis [21]. Although, the presence of waxes in the peel cuticle is an obstacle to drying, it is important to remove it [22]. SEM analysis was used to examine the peel structure of untreated and treated grapes before drying. As an example, in Figure 9 the peel of fresh untreated and treated red grape was shown. The fresh untreated sample exhibited a peel with uniform and compact aspect of waxes (Figure 9(b)). The effectiveness of the abrasive treatment to remove the waxy layer from the grape surface is clear in Figure 9(a), where the waxy layer on the peel of the abraded grape appears almost completely removed, in a quite uniform way.

\subsection{Rehydration Kinetics}

Rehydration is one of the important properties used to measure the quality of raisins [23]. It depends on structural changes in vegetal tissues and cells of food material during drying, which produces shrinkage, collapse and reduces the water absorption capacity, thereby preventing the complete rehydration of the dried product. Samples previously dried over longer periods showed lesser rehydration, indicating the presence of modified structures [6]. Furthermore, the literature reports that different pre treatments had a significant effect on rehydration [24].

The rehydration ratio for white and red grapes was presented in Figure 10. It was observed that both white and red untreated samples showed lesser rehydration ratio after longer drying periods (rehydration ratio of 1.3 in $1400 \mathrm{~min}$ ), indicating the presence of shrunken and closed structures that avoided the diffusion of water inside the raisin. This behavior was confirmed by shrinkage measurements shown in Figure 7 and Figure 8. In particular, the treated red grape showed a rehydration ratio (maximum 3.5 in about 400 min) higher than the treated white grape (maximum 2.3 in $250 \mathrm{~min}$ ).

Table 2. Texture properties of the pretreated and untreated dried grape of the two cultivars.

\begin{tabular}{|c|c|c|c|c|}
\hline \multicolumn{2}{|c|}{ Grape cultivar } & \multirow{2}{*}{$\begin{array}{l}\text { Hardness }(\mathrm{N}) \\
6.30^{\mathrm{a}} \pm 0.26\end{array}$} & \multirow{2}{*}{$\begin{array}{c}\text { Springness (mm) } \\
0.50^{\mathrm{a}} \pm 0.14\end{array}$} & \multirow{2}{*}{$\begin{array}{c}\text { Chewiness }\left(\mathrm{N}^{*} \mathrm{~mm}\right) \\
0.46^{\mathrm{a}} \pm 0.10\end{array}$} \\
\hline & Untreated & & & \\
\hline vйlite gidpe & Treated & $6.33^{\mathrm{a}} \pm 0.13$ & $0.43^{\mathrm{a}} \pm 0.12$ & $0.48^{\mathrm{a}} \pm 0.10$ \\
\hline \multirow{2}{*}{ Red grape } & Untreated & $4.12^{\mathrm{b}} \pm 0.22$ & $0.51^{\mathrm{a}} \pm 0.16$ & $0.34^{\mathrm{b}} \pm 0.08$ \\
\hline & Treated & $4.04^{\mathrm{b}} \pm 0.20$ & $0.44^{\mathrm{a}} \pm 0.11$ & $0.31^{\mathrm{b}} \pm 0.10$ \\
\hline
\end{tabular}

Values on the same column with different superscript letters are significantly different $(p<0.05)$.

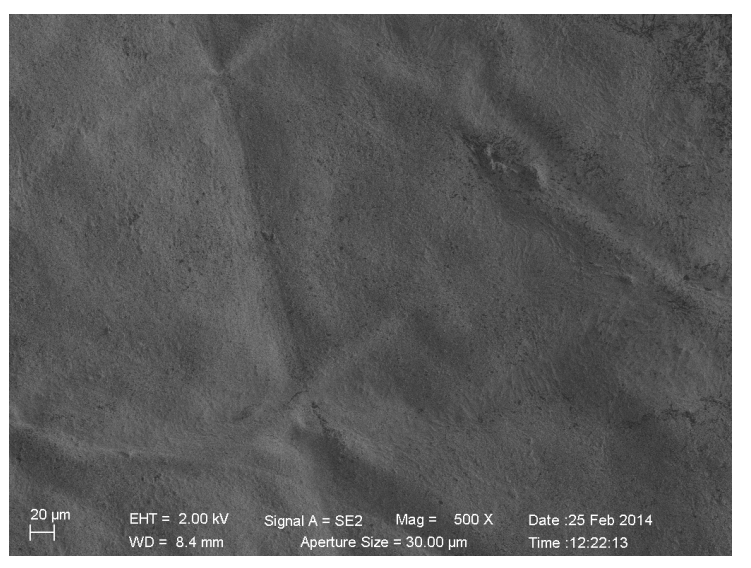

(a)

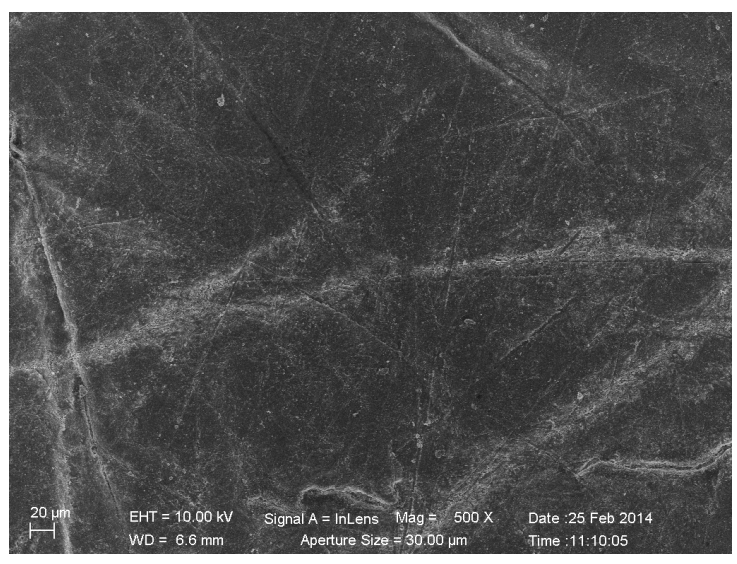

(b)

Figure 9. SEM images (500×) of peel of untreated (a) and treated fresh red grape (b). 


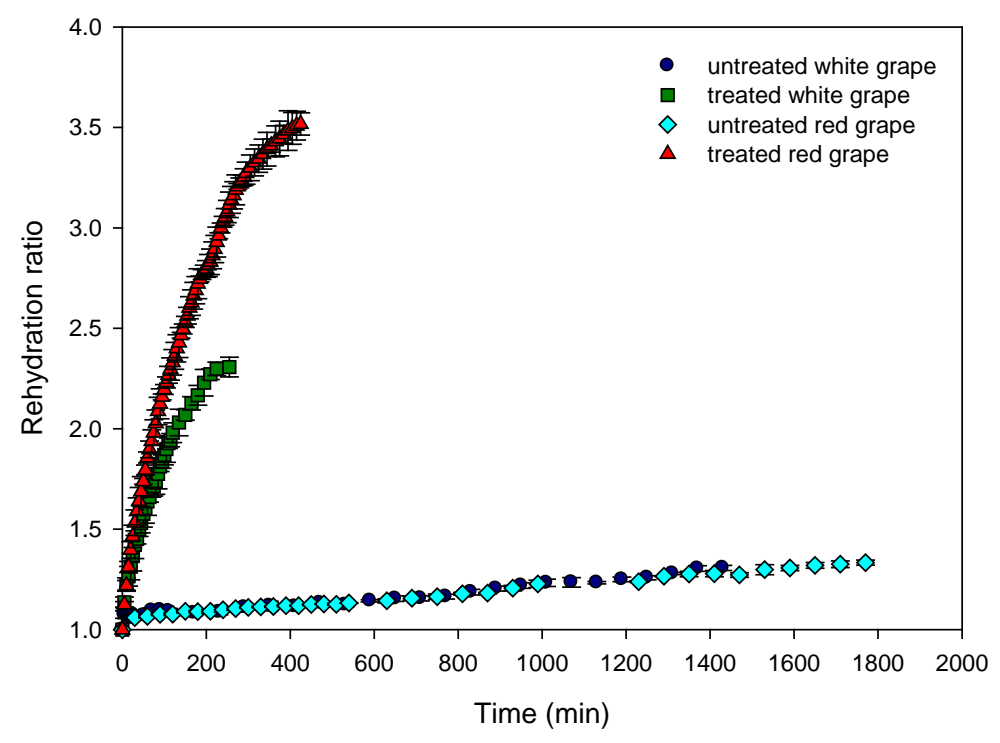

Figure 10. Rehydration ratio for white and red dried samples.

\section{Conclusion}

The effect of abrasive pretreatment on the drying kinetics and quality parameters of Regina and Red Globe grape cultivars was examined in this research. The results showed that the pretreatment affects the drying kinetics of both grape cultivars. The pretreated grapes showed reduced drying times and rehydration time, due to faster transport of water, and lower shrinkage with respect to untreated ones. This is attributed to the lower resistance offered for diffusion of moisture through the peel due to physical treatment, confirmed by SEM measurements. Moreover, pretreated grapes presented lower reduction in sugar content and in tartaric acid, but similar malic and citric acids and texture properties to untreated ones.

\section{References}

[1] Xiao, H.W., Pang, C.L., Wanga, L.H., Bai, J.W., Yang, W.X. and Gao, Z.J. (2010) Drying Kinetics and Quality of Monukka Seedless Grapes Dried in an Air-Impingement Jet Dryer. Biosystem Engineering, 105, 233-240.

[2] Li, L.L., Wang, Z.F., Hu, X.S., Wu, J.H., Liao, X.J., Chen, F. and Zhao, G.H. (2010) Drying Effects of Two Air-Drying Shelters in a Pilot Test on Sultana Grapes. Journal of Food Processing Engineering, 33, 162-178. http://dx.doi.org/10.1111/j.1745-4530.2008.00266.x

[3] Chen, Z., Zhu, C. and Han, Z. (2011) Effects of Aqueous Chlorine Dioxide Treatment on Nutritional Components and Shelf-Life of Mulberry Fruit (Morusalba L.). Journal of Bioscience and Bioengineering, 111, 675-681.

http://dx.doi.org/10.1016/j.jbiosc.2011.01.010

[4] Gowen, A.A., Abu-Ghannam, N., Frias, J.M., Barat, J.M., Andres, A. and Oliveira, J.C. (2006) Comparative Study of Quality Changes Occurring on Dehydration and Rehydration of Cooked Chickpeas (Cicer arietinum L.) Subjected to Combined Microwave-Convective and Convective Hot Air Dehydration. Journal of Food Science, 71, 282-289. http://dx.doi.org/10.1111/j.1750-3841.2006.00082.x

[5] Erenturk, S., Gulaboglu, M.S. and Gultekin, S. (2005) The Effects of Cutting and Drying Medium on the Vitamin C Content of Rose Hip during Drying. Journal of Food Engineering, 68, 513-518. http://dx.doi.org/10.1016/j.jfoodeng.2004.07.012

[6] Russo, P., Adiletta, G. and Di Matteo, M. (2013) The Influence of Drying Air Temperature on the Physical Properties of Dried and Rehydrated Eggplant. Food and Bioproducts Processing, 91, 249-256. http://dx.doi.org/10.1016/j.fbp.2012.10.005

[7] Carranza-Concha, J., Benlloch, M., Camacho, M.M. and Martínez-Navarrete, N. (2012) Effects of Drying and Pretreatment on the Nutritional and Functional Quality of Raisins. Food and Bioproduct Processing, 90, 243-248.

[8] Fava, J., Hodara, K., Nieto, A., Guerrero, S., Alzamora, S.M. and Agueda Castro, M. (2011) Structure (Micro, Ultra, Nano), Color and Mechanical Properties of Vitis labrusca L. (Grape Berry) Fruits Treated by Hydrogen Peroxide, UV-C Irradiation and Ultrasound. Food Research International, 44, 2938-2948. 
http://dx.doi.org/10.1016/j.foodres.2011.06.053

[9] Tarhan, S. (2007) Selection of Chemical and Thermal Pretreatment Combination for Plum Drying at Low and Moderate Drying Air Temperatures. Journal of Food Engineering, 79, 255-260. http://dx.doi.org/10.1016/j.jfoodeng.2006.01.052

[10] Cinquanta, L., Di Matteo, M. and Esti, M. (2002) Physical Pre-Treatment of Plums (Prunus domestica). Part 2. Effect on the Quality Characteristics of Different Prune Cultivars. Food Chemistry, 79, 233-238. http://dx.doi.org/10.1016/S0308-8146(02)00138-3

[11] Bingol, G., Roberts, J.S., Balaban, M.O. and Devres, Y.O. (2012) Effect of Dipping Temperature and Dipping Time on Drying Rate and Color Change of Grapes. Drying Technology, 30, 597-606. http://dx.doi.org/10.1080/07373937.2011.654020

[12] Esmaiili, M., Sotudeh-Gharebagh, R., Mousavi, M.A.E. and Rezazadeh, G. (2007) Influence of Dipping on Thin-Layer Drying Characteristics of Seedless Grapes. Biosystems Engineering, 98, 411-421. http://dx.doi.org/10.1016/j.biosystemseng.2007.09.024

[13] Esmaiili, M., Sotudeh-Gharebagh, R., Mousavi, M.A.E. and Rezazadeh, G. (2007) Grape Drying: A Review. Food Review International, 23, 257-280. http://dx.doi.org/10.1080/87559120701418335

[14] Di Matteo, M., Cinquanta, L., Galiero, G. and Crescitelli, S. (2000) Effect of a Novel Physical Pretreatment Process on the Drying Kinetics of Seedless Grapes. Journal of Food Engineering, 46, 83-89. http://dx.doi.org/10.1016/S0260-8774(00)00071-6

[15] Senadeera, W., Adiletta, G., Di Matteo, M. and Russo P. (2014) Drying Kinetics, Quality Changes and Shrinkage of Two Grape Varieties of Italy. Applied Mechanics and Materials, 553, 362-366. http://dx.doi.org/10.4028/www.scientific.net/AMM.553.362

[16] Albanese, D., Cinquanta, L. and Di Matteo, M. (2007) Effects of an Innovative Dipping Treatment on the Cold Storage of Minimally Processed Annurca Apples. Food Chemistry, 105, 1054-1060. http://dx.doi.org/10.1016/j.foodchem.2007.05.009

[17] Singh, B., Panesar, S.P. and Nanda, V. (2007) Rehydration Kinetics of Un-Osmosed and Pre-Osmosed Carrot Cubes. World Journal of Dairy and Food Sciences, 2, 10-17.

[18] Adiletta, G., Iannone, G., Russo, P., Patimo, G., De Pasquale, S. and Di Matteo, M. (2014) Moisture Migration by Mag-netic Resonance Imaging during Eggplant Drying: A Preliminary Study. International Journal of Food Science and Technology, 49, 2602-2609. http://dx.doi.org/10.1111/ijfs.12591

[19] Brasiello, A., Adiletta, G., Russo, P., Crescitelli, S., Albanese, D. and Di Matteo M. (2013) Mathematical Modeling of Eggplant Drying: Shrinkage Effect. Journal of Food Engineering, 114, 99-105. http://dx.doi.org/10.1016/j.jfoodeng.2012.07.031

[20] Caine, W.R., Aalhus, J.L., Best, D.R., Dugan, M.E.R. and Jeremiah, L.E. (2003) Relationship of Texture Profile Analysis and Warner-Bratzler Shear Force with Sensory Characteristics of Beef Rib Steaks. Meat Science, 64, 333-339. http://dx.doi.org/10.1016/S0309-1740(02)00110-9

[21] Heredia, A. (2003) Biophysical and Biochemical Characteristics of Cutin, a Plant Barrier Biopolymer. Biochimica et Biophysica Acta, 1620, 1-7. http://dx.doi.org/10.1016/S0304-4165(02)00510-X

[22] Pinelo, M., Arnous, A. and Meyer, A.S. (2006) Upgrading of Grape Skins: Significance of Plant Cell-Wall Structural Components and Extraction Techniques for Phenol Release. Trends in Food Science and Technology, 17, 579-590. http://dx.doi.org/10.1016/j.tifs.2006.05.003

[23] Wang, Y., Tao, H., Yang, J., An, K., Ding, S., Zhao, D. and Wang, Z. (2014) Effect of Carbonic Maceration on Infrared Drying Kinetics and Raisin Qualities of Red Globe (Vitis vinifera L.): A New Pre-Treatment Technology before Drying. Innovative Food Science and Emerging Technologies, 26, 462-468. http://dx.doi.org/10.1016/j.ifset.2014.09.001

[24] Gabas, A.L., Menegalli, F.C. and Telis-Romero, J. (1999) Effect of Chemical Pre-Treatment on the Physical Properties of Dehydrated Grapes. Drying Technology, 17, 1215-1226. http://dx.doi.org/10.1080/07373939908917606 